Kohl: a Journal for Body and Gender Research

Vol. 6, No. 2 (Fall 2020)

\title{
Leah Lakshmi Taught Me: my anxious, pandemic-time musings about building for the long-haul
}

Nelly Bassily 
"As I move forward in this life of creating and receiving care, I am continually impressed by how we find ways to keep each other alive when the state is fucked, and community can be fucked and inadequate too."

"I also think about friends and strangers who have plenty of needs but not enough friends or strangers willing and able to come through to care for them. The community is not a magic utopia, just like our families weren't, and we don't all just magically love each other, or even like each other, let alone agree on every political issue."

"I think about the things I still can't ask friends to help me with-cleaning the house when it's incredibly nasty after l've been in pain for weeks, dealing with shit or blood. I think about my friend's statement that she shouldn't have to rely on being liked or loved to get care."

Those are quotes from Leah Lakshmi's book, Care Work: Dreaming Disability Justice. I've been thinking a lot about what care means over these coronavirus months.

Like for example, when I'm having an anxiety attack, all I really want are empathy and care. Many things can trigger my anxiety and those who already know that l'm a rape survivor, know that I've been dealing with trauma, depression, and anxiety. And when I don't feel understood, cared for, and loved, it exhausts me and makes me feel worse. It makes me feel worse about myself, about the world that surrounds me. It exhausts me to have to explain how my trauma-brain gets triggered AF by conversations around lack of understanding of consent, all the way to news stories about not believing victims who denounce their rapists and abusers.

Summer and fall of 2020, I marched alongside other folks to denounce rape culture.

I also marched against police brutality, systemic anti-Black racism, and ongoing colonial injustices against Indigenous folks in Canada.

We can say that 2020 was a shit year but not just because of COVID-19. Folks at the margins, dealing with racism, hetero-patriarchy, and colonial injustices have always known that the world around them is shit. While the COVID-19 global pandemic is mercilessly taking lives - worldometer.info/coronavirus gives you a daily count and as I type this, it reports a worldwide death toll of 1,288,717 - the injustices of racism, colonialism, and heterocispatriarchy have always been of pandemic proportions for those who have always lived them especially for folks who identify as queer and trans, Black, Indigenous, people of colour with disabilities. The difference now is that our COVID-19 reality further marginalizes those who also have to deal with multiple and intersecting systems of oppression. Coronavirus also further isolates us - by forcing us away from our loved ones.

Wear your mask. Keep your distance. Stay home. Shelter in place. Yes, all these things are acts of community love. To not expose ourselves and our loved ones to risks and to do all we can to protect each other and stop the spread of coronavirus is indeed care and love. But, what happens when sheltering in place means further isolation? What happens when staying home alone means your disabled bodymind has to battle depression and anxiety without community supports in the middle of a global fucking pandemic? What happens when 
the rules tell you you shouldn't hug your loved ones anymore if you don't live with them? What happens when the COVID-19 rules discourage you from having many lovers? What happens when the rules that should help you survive COVID simultaneously are awful for your mental health? What happens when at the intersections of disability, fears of police brutality, and lack of community-based frontline resources, you find yourself wishing no one calls the cops on your neighbour with schizophrenia who's been screaming religious hymns at the top of his lungs from sunrise to afternoon, as the police shows up, wanting to handcuff him before even knowing him.

What happens is exactly what Leah Lakshmi wrote in Care Work: "Everyone I know is a mix of on edge, permanently wondering what shit will hit the fan next, trying not to be stuck in reactivity and panic, and sometimes, absurdly hopeful and passionate about building the futures we need."

In August 2019, I recorded an interview with Leah Lakshmi. I gushed about how much I admired Leah and said to her: "I'm so glad we're having this conversation. I'm glad because I am a fan of your writings and admirer of your longtime activism around the politics and realities of Disability Justice work. How grueling but also how joyous this work can be because ultimately doing disability justice work is a radical love of disabled folks. Because as Mia Mingus says, 'Access is Love' and I can't think of a better way to embody love than through care work, because it's the ultimate resistance and the biggest fuck you to able-bodied and abledminded supremacy's normative capitalism, trying to impose productivity-at-all-costs bullshit in your day-today. When I think 'Disability Justice,' I often think about disabled QTBIPOC community uplifting itself against ALL the isms. That said, away from all academic terms and many intersecting isms, I'm interested in knowing what giving and receiving care looks like for you, especially in terms of centering sustainability, slowness, and building for the long-haul?"

And part of Leah's wonderful reply was: "When all we know how to do is quick, quick, quick, quick, it means you're 'on' all the time and everything is an emergency, but that just doesn't work. Over my lifetime, I am somebody who, for a lot of reasons including class, including trauma survivorship, comes from a place where because of my anxiety and my life, everything had to happen right away. But, one thing I have grown into overtime and over witnessing other disabled mentors and peers do is say things like: I will get back to you when spoons allow. And you know what, the world didn't end. But, my default is the panic, crisis response 'I've got to be up till three or the world will end' and then I saw examples of people who were like, 'hey, you can only do what you can do' and they were accomplishing a lot as disabled people."

Building for the long-haul and slowness, I think about that a lot. Much like Leah, in a world designed to exclude, I think about what it means to deprogram myself from panic, urgency, and doom when my anxious mind and thoughts want to take me there. If I zoom out onto the world, I think, that's what the punishmentcentered injustice system has taught us to do: panic and fear each other. But who does that serve? How do I really take the time to know my neighbours and strangers? How do I truly build community? If I want a world where the fall of racism, colonialism, capitalism, ableism, trans and queerphobia, xenophobia, and patriarchy has happened, maybe building for the long-haul also means placing the building blocks so that in the year 2277, folks will read in history books about how 257 years ago, in the year 2020, QTBIPOC folks with 
Kohl 6.2

186 disabilities pushed for free and accessible housing for all, demanded that we defund the police, took to the streets to say enough to rapists and abusers, came together in mutual aid groups to help their neighbours survive a global pandemic, etc. And the folks from 2277 will look at us and think, thank you for creating the ground wells that led to our collective liberation. 